\title{
SURFACE TEXTURE ANALYSIS OF A JOINT SAMPLE BY 2D AND 3D SURFACE ROUGHNESS PARAMETERS
}

\author{
K. Maňas*, J. Hnidka**, V. Tř́́ska***
}

\begin{abstract}
This paper presents a year-long research after the aviation accident, which happened in the Czech Armed Forces. During this accident, the helicopter Mi-171 was severely damaged. This paper contains an analysis of microgeometric properties (2D and 3D) of the part of the helicopter's Mi-171 main gear, which failed during landing. The main gear contains a horizontal front strut, which is mounted to the fuselage via a coupling element in form of a cardan joint. The failure of this joint was ultimately responsible for the accident. This paper compares the qualitative properties of the joint manufactured by the Czech manufacturer and a former Soviet Union one. This paper also presents a 3D surface topography of both joint and investigates $3 D$ surface parameters as an extension of a $2 D$ surface parameters.
\end{abstract}

Keywords: surface analysis; 3D surface topography; surface structure; surface roughness.

\section{Introduction}

Maňas (2010) defines quality, in terms of engineering, from the perspective of manufacturing technology, as the exactness of dimensions, exactness of geometric shape and location, surface waviness and surface roughness, all depending on the chemical and physical properties of the machine part. To properly evaluate the quality of the machine part, it is necessary to correctly choose and perform a number of different tests, which can reveal possible cause of failure. The analysis of the service life of the failed joint showed that the joint manufactured by the Czech manufacturer has a shorter service life than the original Soviet joint. This prompted the comparison of the quality of both joints. Quality was partially assessed by Maňas et al. (2018); however, this paper further advances the research by presenting the results obtained by a 3D surface topography. Maňas et al. (2018) assumed that the difference between both machining parts was in the method of machining - specifically, the former Soviet Union manufacturer forged the joint, while the joint manufactured by the Czech manufacturer was milled. This paper shows that the 3D surface topography can be used as an indicator of different machining processes.

The material analysis, performed prior to this research, revealed the material properties such as hardness, microhardness, chemical composition and microstructure of the material. As Maňas et al. (2018) assessed, both parts seemed to be identical in almost every test, the chemical composition and structure was the same. The material properties tests, unlike the microgeometry tests, might not reveal differences in technology of manufacturing process of the joint. However, based on the results of the tests, it was safe to assume that the stock was identical for both Czech and Soviet joint.

The Czech joint sample in this paper is referred to as LOM, while the Soviet part is 93BS.

\section{2D Microgeometric Analysis}

To evaluate the quality of the surface of both joint samples 93BS and LOM, the microanalysis of the surface by measurement of $2 \mathrm{D}$ parameters of surface roughness was chosen.

\footnotetext{
* Ing. Karel Maňas, PhD.: University of Defence, Kounicova 65; 602 00, Brno; CZ, karel.manas@unob.cz

** Ing Jakub Hnidka, Ph.D.: University of Defence, Kounicova 65; 602 00, Brno; CZ, jakub.hnidka@gmail.cz

*** Ing. Václav Tř́íska, Ph.D.: University of Defence, Kounicova 65; 602 00, Brno; CZ, vaclav.triska@unob.cz
} 
Measurement of the surface roughness of both joint samples was conducted with a surface roughness tester Talysurf CLI 1000. The measurement system Talysurf CLI 1000 allows to measure surface texture by two methods: contact method with induction sensor or non-contact method with confocal sensor. The measurement was contact-type and absolute. The measured distance was $4 \mathrm{~mm}$ for first measurement and $12.5 \mathrm{~mm}$ for second measurement for both joint samples.

Results from $4 \mathrm{~mm}$ long measurement (as recommended by standards ISO 4287, ISO 4288) are not presented in this paper, because the $12.5 \mathrm{~mm}$ long measurement has higher accuracy.

The parameter $R a$ was used to evaluate the surface roughness of both joint samples. This parameter is perhaps the most common surface roughness parameter. By its nature, it depends on the amplitude of the roughness - it is the mean arithmetic deviation of the measured surface. This parameter is not as sensitive to surface peaks and valleys of a $2 \mathrm{D}$ profile of surface roughness. Therefore, it does not assess the surface roughness correctly.

From Fig. 1 and 2. it is apparent that measured parameters have both same value of $R a=2.17$. While both samples have the same value of surface roughness parameter $R a$, there are obvious differences in 2D profiles of surface roughness of samples 93BS (Fig. 1) and LOM (Fig. 2). Surface roughness profile of the joint sample 93BS contains significantly more peaks. Contrary to this, the surface roughness profile of the joint sample LOM contains more valleys than peaks.

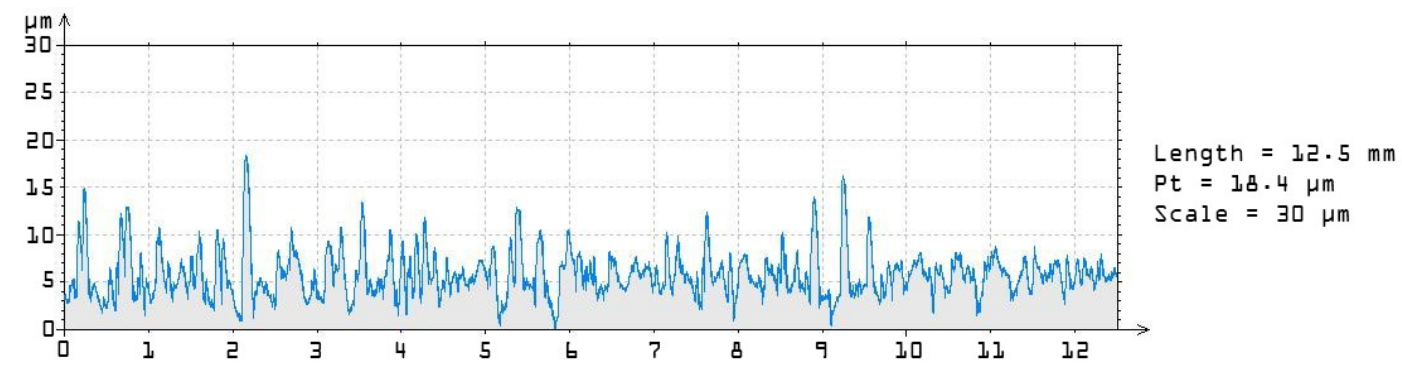

Fig. 1: 2D surface roughness profile of joint sample 93BS

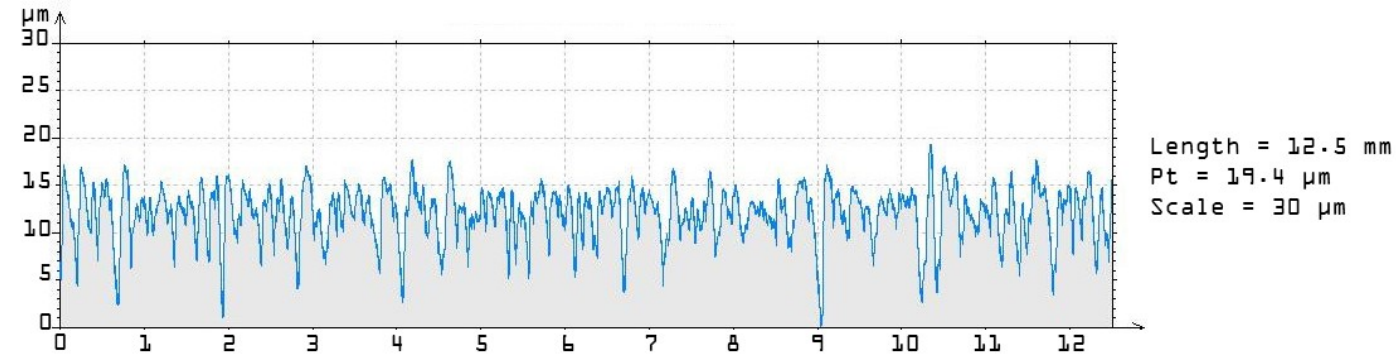

Fig. 2: 2D surface roughness profile of the joint sample LOM

Because the surface roughness parameter $R a$ does not correctly asses the actual surface roughness of the joint samples, it was decided to choose more appropriate, although, arguably, more uncommon parameters. The selected parameters are so called functional 2D surface roughness parameters: $R k, R p k$ and $R v k$. Parameter $R v k$ expresses the base depth of the core of the surface roughness profile (the area with the largest increase of the material portion above the given depth) and it is used as a parameter to assess the quality of mechanically loaded parts. Parameter $R p k$ is called peak reduction and it expresses the mean height of peaks of the surface roughness profile. Parameter $R v k$ is reduced depth of valleys and it assesses the mean depth of the valleys of the surface roughness profile.

Fig. 3 and Fig. 4 all assess the $R k$ parameter of surface roughness. It is obvious that the base depth of the core of the surface roughness profile $R k$ is the same for both joint samples. Nonetheless, every other parameter reaches different values. Joint sample 93BS has the $R p k$ parameter larger than $R p k$ measured at joint sample LOM. It is possible to observe the considerably different multiplicity parameter for both joint samples. The measurement results show that the joint sample LOM has more valleys than joint sample 93BS.

The surface roughness of parts and components depends heavily on the manufacturing technology and machining process. The joint sample 93BS shows no signs of chip formation, such as milling. This does correspond well with the measured values of surface roughness and its nature. It is reasonable to assume 
that the joint sample 93BS was manufactured by forging. On the other hand, the joint sample LOM was very likely milled. These different machining technologies have an impact on the surface roughness structure, as demonstrated by the values of surface roughness parameter $R k$.

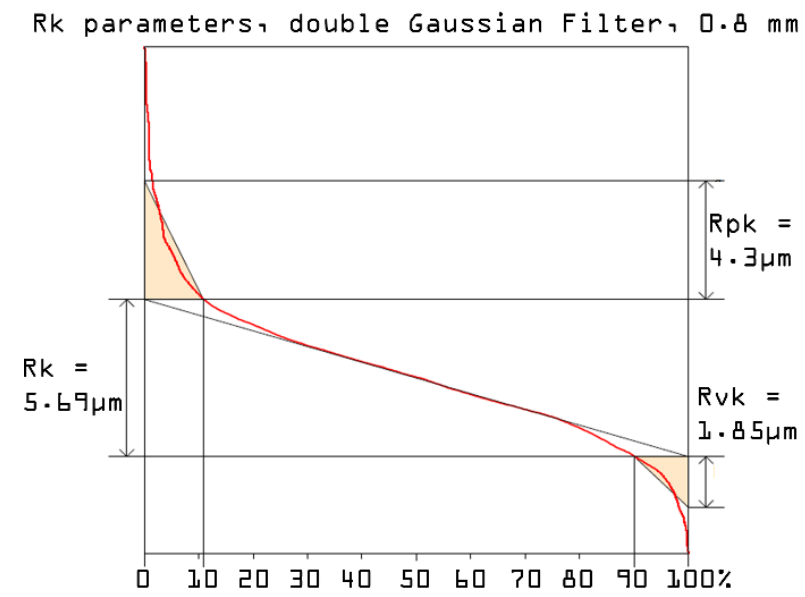

Fig. 3: Rk parameter of sample 93BS

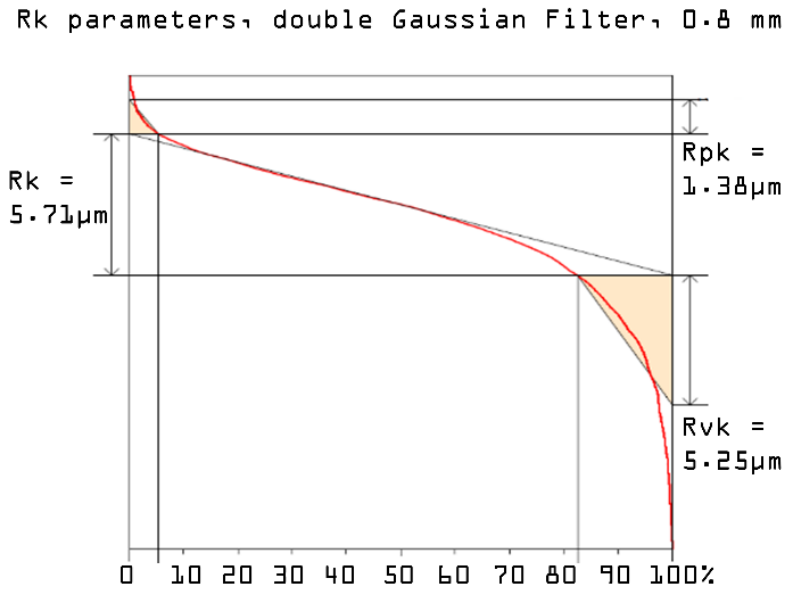

Fig. 4: Rk parameter of sample LOM

\section{3D Microgeometric Analysis}

Talysurf CLI 1000 was used to perform the 3D surface topography by the non-contact method CLA with confocal sensor. Both joint samples were measured with the cut-off value $\Lambda \mathrm{c}$ equal to $0.8 \mathrm{~mm}$ (ISO 4228) with the base and evaluated length of $4 \times 4 \mathrm{~mm}$.

Figures 5 and 6 show 3D surface topography of joint samples 93BS and LOM. Even without close examination, it is apparent that both surfaces are different. Joint sample 93 has irregular surface structure with peaks and valleys distributed randomly along the evaluated surface area. The joint sample LOM has a more regular structure of the surface texture, where the peaks and valleys repeat periodically. There is an observable relation between this repetition and the cutting conditions of the cutting tool used during the manufacturing process. The manufacturing process of both joint samples was, therefore, different. This is confirmed by the values measured during the 3D surface topography, shown in the Table 1.

The joint sample 93BS is most likely forged, which is confirmed by the 3Dsurface roughness parameter $\mathrm{Sa}$ equal to $2.416[\mu \mathrm{m}]$. The joint sample LOM was milled. The surface roughness parameter $S a$ of joint sample LOM is considerably larger $(2.658[\mu \mathrm{m}])$ than that of joint sample 93BS. It is apparent that the Czech manufacturer tried to achieve the same value of roughness parameter, but without using the proper and required manufacturing process it failed to manufacture a product with the same surface topography.

Tab. 1: Parameters of the 3D surface roughness of the surface topography of joint samples 93BS and LOM

\begin{tabular}{|c|c|c|c|c|}
\hline $\begin{array}{c}\text { Joint } \\
\text { sample }\end{array}$ & $\boldsymbol{S a}[\boldsymbol{\mu m}]$ & $\boldsymbol{S k}[\boldsymbol{\mu m}]$ & Spk $[\boldsymbol{\mu m}]$ & $\boldsymbol{S v k}[\boldsymbol{\mu m}]$ \\
\hline 93 BS & 2.416 & 4.548 & 2.076 & 2.237 \\
\hline LOM & 2.658 & 8.225 & 1.248 & 2.741 \\
\hline
\end{tabular}




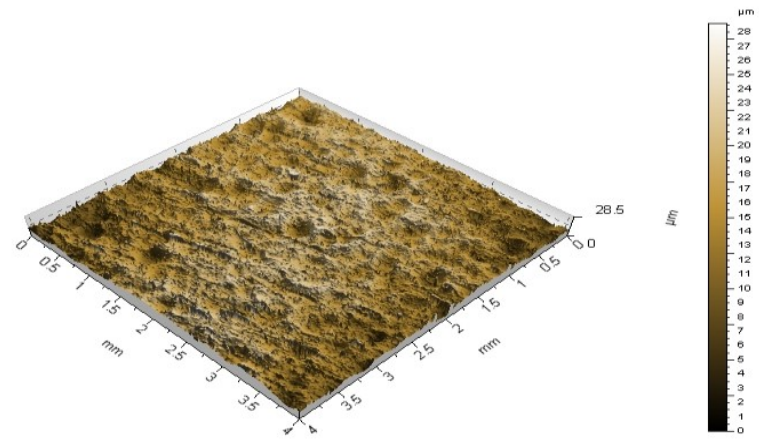

Fig. 5: 3D surface topography of the joint sample 93BS

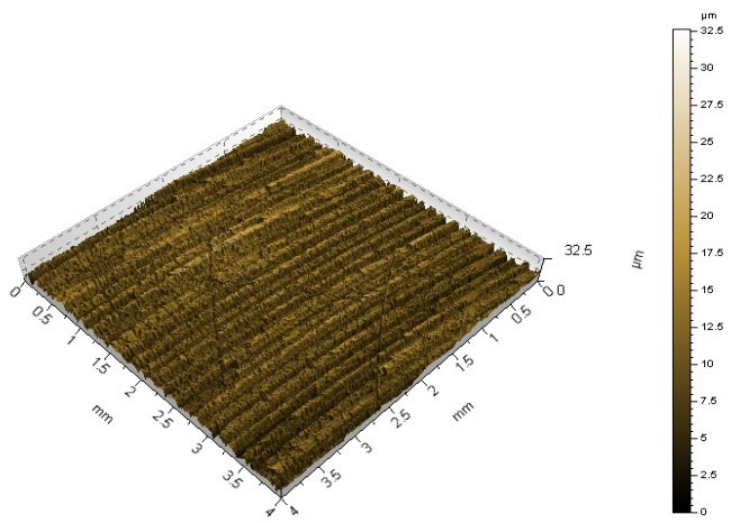

Fig. 6: 3D surface topography of the joint sample LOM

\section{Conclusions}

The paper assesses the microgeometric properties of two joint samples, one manufactured by Czech manufacturer (LOM), while the other by a Soviet one (93BS). This paper presents a research following the aviation accident, where this joint failed during landing.

The surface structure of both joints has been mapped and the results confirm that the Czech manufacturer made the joint using chip machining, while the Soviet manufacturer used chipless machining (forging).

Surface roughness of both joints was assessed by both 2D and 3D parameters. 2D parameters pointed to the manufacturing process differences and the 3D parameters confirmed the hypothesis. However, the most common surface roughness parameter $R a, S a$ failed to properly assess the surface roughness, because of their inherent deficiency caused by the fact that both are mean values of the surface texture and are not as sensitive to the peaks and valleys. $R k$ and $S k$ parameters are much more suitable for this application.

\section{References}

Maňas, K. (2010) Evaluation of Systems Analyzing the Surface Texture. Dissertation, Brno.

Maňas, K., Hnidka, J., Tř́ska, V. and Junas, M. (2019) Analysis of the damaged aircraft component after impact caused by harsh landing. International Conference on Military Technology ICMT 2019.

ČSN EN ISO 4287 Geometrical Product Specifications (GPS) - Surface texture: Profile method -Terms, definitions and surface texture parameters

ČSN EN ISO 4288 Geometrical product specification (GPS) - Surface texture: Profile method -Rules and procedures for the assessment of surface texture 